\title{
Misperceptions about "light" cigarettes among smokers in Zambia: Findings from the International Tobacco Control (ITC) Zambia Survey
}

\author{
Susan C Kaai ${ }^{1}$, Geoffrey T Fong ${ }^{1,2}$, Annika C Green ${ }^{1}$, Fastone Goma ${ }^{3}$, Gong Meng ${ }^{1}$, Anne CK Quah ${ }^{1}$, Ron \\ Borland", Masauso M Phiri, Tora Elton-Marshal15,6,7
}

\begin{abstract}
INTRODUctION Little is known about beliefs about "light" cigarettes ("lights") in African countries where both tobacco industry activity and tobacco control efforts are intensifying. This study in Zambia is the first to examine the prevalence and beliefs about "lights" among smokers in Africa. METHODs Data are from 1,214 smokers participating in the International Tobacco Control (ITG) Zambia Wave 1 Survey (2012), a multi-stage clustered sampling design, face-to- face nationally representative probability sample of tobacco users and non-users aged 15 years and older. RESULTS $17.0 \%$ of respondents' usual brand of cigarettes was "lights". 36.5\% of smokers believed that "lights" are less harmful; beliefs differed by brand type (42.1\% "lights" vs. $38.2 \%$ "non-lights"). $42.0 \%$ of smokers believed that "lights" are smoother on the throat and chest than regular cigarettes with beliefs differing by brand type. Among smokers who believed that "lights" are smoother, $81.0 \%$ believed that these cigarettes are less harmful, much higher than the $4.1 \%$ of smokers who did not believe that "lights" are smoother. Smoothness beliefs about "lights" was the strongest predictor of the belief that "lights" are less harmful ( $\mathrm{p}<0.001, \mathrm{OR}=131.13,95 \%$ CI 59.4 to 289.5).

concLusions Zambian smokers incorrectly believe that "lights" are less harmful. The highly strong association between the belief that "lights" are smoother and the belief that "lights" are less harmful suggests that tobacco control policies need to use a multi-pronged approach including product regulation, banning misleading descriptors and menthol, and implementing sustained longterm public education campaigns to combat sensory beliefs and misperceptions about "lights".

AFFILIATION
1 Department of Psychology,
University of Waterloo,
Waterloo, Ontario, Canada
2 Ontario Institute for Cancer
Research, Toronto, Ontario,
Canada
3 School of Medicine, University
of Zambia, Lusaka, Zambia
4 Cancer Council Victoria,
Melbourne, Victoria, Australia
5 Social and Epidemiological
Research Department, Centre
for Addiction and Mental Health,
London, Ontario, Canada
6 Dalla Lana School of Public
Health, University of Toronto,
Toronto, Ontario, Canada
7 Department of Epidemiology
and Biostatistics, Western
University, London, Ontario,
Canada
KEYword
Tobacco, Predictors, Zambia,
Lights, Mild, Smooth
Dr. Susan C Kaai, Department
of Psychology, University of
Waterloo, Waterloo, Ontario,
Canada, 200
University Avenue West, N2L
EGl Waterloo, Ontario, Canada.
Email: skaai@uwaterloo.ca
\end{abstract}

Tob. Prev. Cessation 2016;2(September):69 http://www.dx.doi.org/10.18332/tpc/64947

\section{INTRODUCTION}

Despite the fact that cigarettes described as "light" or "low tar" do not reduce health risks compared to regular brands, many smokers continue to believe that they are less harmful ${ }^{1-5}$. Filtervented "light" cigarettes ("lights") were initially introduced in Western countries to persuade increasingly health concerned smokers that they could reduce their health risks by smoking cigarettes that were apparently less harmful ${ }^{6}$. Although "lights" were purported to be less harmful because they generally deliver less tar under the International Organization for Standardization/Federal Trade Commission (ISO/FTG) machine testing ${ }^{6}$, these testing methods are not an accurate measure of actual delivery of harmful smoke constituents under real smoking conditions ${ }^{7}$. The filter vents dilute the tobacco smoke with air, thereby reducing tar levels in ISO/ FTC testing ${ }^{8,9}$. However, smokers craving nicotine adjust their smoking behavior to compensate for the lower nicotine and consequently inhale higher levels of harmful smoke constituents. Compensatory behaviors include blocking filter vents with fingers ${ }^{10}$, increasing cigarette consumption ${ }^{11}$ and increasing puff volumes and frequency of puffs ${ }^{10,12}$. Hence, "lights" or "low tar" cigarettes are no less harmful compared to 
regular brands ${ }^{13-15}$. Although filter-vented "lights" began as a marketing strategy in the West, the concept has been adopted and marketed to varying degrees internationally, typically as the market becomes more 'sophisticated' and becomes increasingly concerned about the health consequences of smoking. The majority of the research examining beliefs about "lights" has been conducted in Western and high-income countries (HICs) and rarely in low- and middle-income countries (LMICs). Beliefs about the harmfulness of "lights" differed widely among smokers in Malaysia compared to Thailand. In Malaysia, 19\% of smokers believed that "lights" are less harmful than regular cigarettes compared to $46 \%$ of smokers in Thailand ${ }^{3}$. In China, $71 \%$ of smokers believed that "lights" or "low tar" cigarettes were less harmful than full-flavored cigarettes ${ }^{2}$. The differences in the belief that "lights" are less harmful by country are likely reflective of the differences in how "lights" are marketed. For example, in China, a key tobacco industry strategy is to market "lights" and "low tar" cigarettes as less harmfull ${ }^{16}$. Given differences in beliefs about "lights" by country, it is important to examine country level differences to determine whether smokers believe that "lights" are less harmful, and to inform strategies to change misperceptions. One policy strategy that has been widely adopted is a ban on misleading descriptors such as "lights" or "low tar" under Article 11 of the World Health Organization (WHO) Framework Convention on Tobacco Control (FCTC). To date, 95 countries have adopted bans on such descriptors as part of the WHO FCTC ${ }^{17}$. It is estimated that $3 \%$ of all deaths in the African Region among adults aged 30 years and older were attributed to tobacco use ${ }^{18}$. The mean prevalence of tobacco smoking among adults in this Region is estimated to be $21 \%$ for males and $3 \%$ for females (some countries have a prevalence of up to $48 \%$ for males and $20 \%$ for females) ${ }^{19}$. Without comprehensive tobacco prevention and control policies, this prevalence is expected to significantly increase by $2030^{20}$. According to the 2013-14 Zambia Demographic Health Survey, the prevalence of tobacco use among adults aged 15-49 years in Zambia is 19.3\% among males and 1.6\% among females ${ }^{21}$. Use of roll-your- own (RYO) cigarettes and the prevalence of concurrent use of RYO and factory made (FM) cigarettes is high $^{22}$. Although Zambia ratified the WHO FCTC in May $2008^{23}$, Zambia has yet to ban the use of misleading descriptors such as "mild" or "extra mild" on tobacco packages as required under Article $11^{24}$. Advertising is not banned in Zambia, thus the public is exposed to "mild" and "extra mild" descriptors through various avenues including the large Pall Mall and Peter Stuyvesant "mild" and "extra mild" cigarette branded billboards that can be found on the major roads in Zambia. These cigarette brands and others are also marketed via newsprint and entertainment media. Most research evidence, however, suggests that bans on descriptors alone may not be sufficient ${ }^{5}$. Evidence from China demonstrates that the most important factor associated with the belief that "lights" are less harmful is the belief that "lights" are smoother on the respiratory system $(\mathrm{OR}=53.87)^{2}$ than regular cigarettes. Of those smokers who believed that "lights" are smoother, 90.9\% said that these cigarettes are less harmful than regular cigarettes ${ }^{2}$. However, further evidence is needed to determine to what extent the very strong linkage between the belief that "lights" are smoother and that "lights" are less harmful generalizes to African countries, such as Zambia, given possible differences in the product design, packaging and marketing of cigarettes. As the tobacco industry continues to mobilize their efforts to build their markets in Africa, efforts to combat tobacco use are growing as well, and with such efforts, there is a need for tobacco control research that focuses on documenting and understanding the factors that are related to tobacco use, beliefs, attitudes, and other psychosocial variables that have been shown to be important in other countries. The current study is the first study to examine use of and beliefs about "lights" among smokers in the African region. The study will provide the evidence needed to inform Zambian tobacco control policy related to misperceptions of "lights".

\section{METHODS}

\section{Study design}

The International Tobacco Control (ITC) Zambia Survey is a longitudinal cohort survey of a face-to- face nationally representative probability sample of 1,470 tobacco users (including smokeless users) and 594 non-users of tobacco aged 15 years and older. The ITC Zambia Survey is part of the larger International Tobacco Control Policy Evaluation Project (the ITC Project) ${ }^{26}$, which consists of parallel longitudinal cohort surveys in 22 countries to evaluate WHO FCTC policies. Data are from Wave 1 of the ITC Zambia Survey conducted from September to December 2012.

\section{Participants and survey procedures}

Participants were selected through a multi-stage clustered sampling design. Specifically, the design was stratified by province and sampling was conducted in a total of 150 enumeration areas (EA), allocated to the provinces in numbers proportional to population size. In each of the 10 provinces, two districts were sampled. Within each district, two wards were sampled except in Lusaka district (the capital), where 
four wards were sampled. Within each ward, EAs were sampled with inclusion probability proportional to size. The quota for each EA was 10 tobacco users and 4 non-users. This was a face-to- face survey and it was administered in 5 local languages: Bemba, Nyanja, Kaonde, Tonga, and Lozi. Survey questionnaires in English were also provided for respondents who wished to answer the survey questionnaire in English. Further details are provided elsewhere ${ }^{27}$. For this paper, only smokers were included in the analyses. Smokers were defined as those who smoked 100 or more cigarettes in their lifetime, smoked at least once in the past 30 days, and had smoked FM cigarettes and/or RYO cigarettes. A total of 1,214 smokers were included in this study. Informed consent was obtained prior to interviews. Research ethics approval was obtained from the Office of Research at the University of Waterloo, Canada, and from the University of Zambia Biomedical Research Ethics Committee.

\section{Measures}

Outcome variable: Belief about the harmfulness of "light" cigarettes

To ensure that respondents understood the definition of "light" cigarettes, interviewers read the following: "Over the years tobacco companies have distinguished what they call "regular" or "full-flavored" cigarettes from others variously described as "light" or "mild". For the following questions, we will refer to all types of "light" or "mild" cigarettes as "light cigarettes." Respondents were then asked whether "Light cigarettes are less harmful than regular cigarettes". Responses were dichotomized where "strongly agree" and "agree" were coded as 1 and "neither agree nor disagree", "disagree", "strongly disagree", or "don't know" were coded as 0 . Refusals $(n=7)$ were excluded from the analyses.

\section{Smoothness Beliefs}

To assess the belief that "light" cigarettes are smoother, respondents were asked whether "Light cigarettes are smoother on your throat and chest than regular cigarettes." Responses were dichotomized where "strongly agree" and "agree" were coded as 1 and "neither agree nor disagree", "disagree", "strongly disagree", or "don't know" were coded as 0 .

\section{Demographic Variables}

Demographic measures included: sex, age (15-24, 25-39, 40-54, and 55+), household monthly income (low: <200 Kwacha (<USD 37.8), moderate: 200-250 Kwacha (USD 37.8- 47.3), high: >250 Kwacha (>USD 47.3), no response), and education (low: illiterate and kindergarten, moderate: some primary/completed primary, high: secondary school or higher).

\section{Knowledge of harms of tobacco use}

To assess knowledge about the health effects of smoking, respondents were asked whether smoking cigarettes causes: stroke, impotence in male smokers, mouth cancer, throat cancer, lung cancer, heart disease, chronic obstructive pulmonary disease (COPD), and tuberculosis. Responses were coded $1=$ yes and $0=$ no/don't know $/$ refused. The eight coded responses were summed $(0=$ no knowledge to $8=$ high level of knowledge). The standardized ordinal alpha for this summation was 0.94 , indicating that this measure is highly reliable.

\section{Concern about health, perceived addiction and health status}

Respondents were asked two questions to assess health concerns: "To what extent, if at all, has smoking cigarettes damaged your health?" (not at all, a little, a lot, and no answer) and "How worried are you, if at all, that smoking cigarettes will damage your health in the future?" (not at all worried, a little worried, moderately worried, very worried, and no answer). Respondents were also asked whether they considered themselves to be addicted to cigarettes (not at all addicted, somewhat addicted, and very addicted, and no answer) and to rate their health (poor, average, good, excellent, and no answer).

\section{Smoking behaviors}

Nicotine dependence was measured using the Heaviness of Smoking Index (HSI) ${ }^{28,29}$, which was based on the sum of two categorical variables: number of cigarettes smoked per day ( scored as $0=0-10$ cigarettes per day (CPD), $1=11-20 \mathrm{CPD}$, $2=21-30 \mathrm{CPD}, 3=\geq 31 \mathrm{CPD}$ ) and time to first cigarette after waking ( scored as $0=>60$ minutes, $1=31-60$ minutes, $2=$ 6-30 minutes, $3=5$ minutes or less). HSI scores ranged from $0=$ least addicted to $6=$ most addicted.

\section{Cigarette Brand Information}

To assess the type of cigarettes smoked, respondents were asked whether they smoked FM cigarettes, RYO cigarettes, or both. The variety of brand usually smoked coded as: $1=$ "lights" usual brand (if respondents had a usual brand that was "mild" or "extra mild"); 2 = "Non-lights" usual brand (if respondents had a usual brand that was regular, strong, or other), and $3=$ no usual brand (if respondents stated that they did not have a usual brand). 


\section{Statistical Analysis}

Analyses used survey weights and adjusted for strata (provinces) and clustering (primary sampling units, districts). More details on weight construction are described elsewhere ${ }^{27}$. Descriptive statistics were calculated using SAS PROC SURVEYFREQ. Survey logistic regression models using SAS PROC SURVEYLOGISTIC were used to test the association between each factor and the belief that "lights" are less harmful. Model 1 tested the association of all covariates (except the smoothness variable) with the outcome variable. Model 2 added the belief that "lights" are smoother than regular cigarettes into the model to determine the unique contribution of this belief after controlling for all covariates. One interaction term (i.e., "lights"/"non-lights" users* smoothness) was also added to Model 2.

\section{RESULTS}

\section{Somple characteristics}

Sample characteristics are presented in Table 1 . The majority of respondents were male (94.6\%), reflecting the disproportionate prevalence of smoking among males in Zambia. The highest proportion of respondents (46.0\%) smoked FM cigarettes only, whereas $30.2 \%$ exclusively smoked RYO cigarettes and $23.3 \%$ smoked both types. About one fifth (17.0\%) of respondents reported that their usual brand was "lights".

\section{Beliefs about "lights"}

Table 2 presents weighted frequencies of respondents' beliefs that "lights" are less harmful and smoother by brand variety. Overall, 36.5\% of Zambian smokers believed that "lights" are less harmful than regular cigarettes and $42.0 \%$ believed that "lights" are smoother on the throat and chest than regular cigarettes. A significantly greater proportion of "lights" smokers (50.6\%) reported that "lights" are smoother on the throat and chest than "non-lights" brand smokers (44.7\%) $(\mathrm{p}=0.01)$. A bivariate analysis showed that location (urban/ rural) was not associated with the belief that "lights" are less harmful than regular cigarettes (data not shown). Table 3 showed that among those smokers who held both beliefs (i.e., believed that "lights" were smoother and also believed that "lights" were less harmful than regular cigarettes), there was no significant difference in beliefs between "lights" (80.4\%) and "non-lights" (81.2\%) users.

\section{Predictors of the belief that "lights" are less harmful}

Table 4 presents the weighted logistic regression analysis to identify the factors associated with the belief that "lights" are less harmful than regular cigarettes. Findings were similar
Table 1. Characteristics of unweighted sample of Zambian smokers $(n=1,214)$

\begin{tabular}{|c|c|c|}
\hline Characteristic & Frequency & $\%$ \\
\hline \multicolumn{3}{|c|}{ Sex } \\
\hline Male & 1148 & 94.6 \\
\hline Female & 66 & 5.4 \\
\hline \multicolumn{3}{|c|}{ Age } \\
\hline $15-24$ & 206 & 17.0 \\
\hline $25-39$ & 510 & 42.0 \\
\hline $40-54$ & 290 & 23.9 \\
\hline $55+$ & 208 & 17.1 \\
\hline \multicolumn{3}{|c|}{ Income } \\
\hline Low $(<200$ ZMW $)$ & 581 & 47.9 \\
\hline Moderate (200- $250 \mathrm{ZMW})$ & 151 & 12.4 \\
\hline High (>250 ZMW) & 314 & 25.9 \\
\hline Not stated & 168 & 13.8 \\
\hline
\end{tabular}

Education

$\begin{array}{lcc}\text { Low (illiterate/kindergarten) } & 134 & 11.0 \\ \begin{array}{l}\text { Moderate (some primary/completed } \\ \text { primary) }\end{array} & 615 & 50.7 \\ \begin{array}{l}\text { High (secondary or higher) } \\ \text { Not stated }\end{array} & 455 & 37.5 \\ & 10 & 0.8\end{array}$

$\begin{array}{lll}0 & 94 & 7.7\end{array}$

$1 \quad 60 \quad 4.9$

$\begin{array}{llll}2 & 94 & 7.7\end{array}$

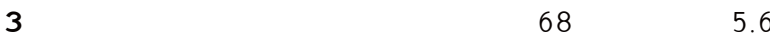

$4 \quad 97 \quad 8.1$

$5 \quad 101 \quad 8.3$

$\begin{array}{lll}6 & 262 & 21.6\end{array}$

$\begin{array}{lll}7 & 232 & 19.1\end{array}$

$8 \quad 206 \quad 17.0$

$\begin{array}{lll}\text { Poor } & 124 & 10.2\end{array}$

Average $\quad 416 \quad 34.3$

Good $\quad 552 \quad 45.5$

$\begin{array}{lll}\text { Excellent } & 95 & 7.8\end{array}$

Not stated $27 \quad 2.2$

Heaviness of Smoking Index (HSI)

$\begin{array}{lll}0-2 & 790 & 65.1\end{array}$

$\begin{array}{lll}3-6 & 327 & 26.9\end{array}$

$\begin{array}{lll}\text { Not stated } & 97 & 8.0\end{array}$

Not at all addicted $\quad 354$

Yes, somewhat addicted $\quad 456 \quad 37.6$

$\begin{array}{lll}\text { Yes, very addicted } & 397 & 32.7\end{array}$

$\begin{array}{lll}\text { Not stated } & 7 & 0.6\end{array}$ 
when the exclusive RYO smokers were included or excluded in the regression analysis; therefore we opted to present findings that included all smokers (i.e., included exclusive RYO smokers). Younger respondents were significantly less likely to believe that "lights" are less harmful. Respondents who were more educated (high vs. low: $\mathrm{p}=0.02, \mathrm{OR}=2.09$, 95\% CI 1.11-3.94), worried that smoking had damaged their health (a little worried vs. not at all worried: $\mathrm{p}=0.05, \mathrm{OR}=$ 1.45, 95\% CI 1.00-2.11), smoked exclusively FM cigarettes (FM only vs. exclusively RYO: $\mathrm{p}<0.001, \mathrm{OR}=2.90,95 \%$ CI 1.89-4.45) or smoked both types of cigarettes (both FM and RYO vs. exclusively RYO: $\mathrm{p}=0.004$, OR $=2.15,95 \%$ CI 1.29 3.61) were significantly more likely to believe that "lights" are less harmful. The association between the belief that "lights" are smoother on the throat and chest and the belief that "lights" are less harmful was tested after controlling for all other covariates (Model 2). Table 4 also highlights the very strong relation between smoothness beliefs and harmfulness beliefs. Specifically, $81.0 \%$ of smokers who agreed or strongly agreed that "lights" are smoother also believed that "lights" are less harmful, whereas only $4.1 \%$ of those who did not believe that "lights" are smoother believed that "lights" are less harmful, corresponding to a very high correlation of $\mathrm{r}=$ 0.788 between the two beliefs, associated with an unadjusted odds ratio of 99.22. In the multivariate model, controlling

\section{Smoking has damaged health}

\begin{tabular}{|c|c|c|}
\hline Not at all & 450 & 37.1 \\
\hline A little & 361 & 29.7 \\
\hline A lot & 283 & 23.3 \\
\hline Not stated & 120 & 9.9 \\
\hline \multicolumn{3}{|c|}{ Smoking will damage health } \\
\hline Not at all worried & 270 & 22.2 \\
\hline A little worried & 237 & 19.5 \\
\hline Moderately worried & 150 & 12.4 \\
\hline Very worried & 523 & 43.1 \\
\hline Not stated & 34 & 2.8 \\
\hline \multicolumn{3}{|c|}{ Brand Variety } \\
\hline "Lights" usual brand & 206 & 17.0 \\
\hline "Non-lights" usual brand & 482 & 39.7 \\
\hline No usual brand & 526 & 43.3 \\
\hline \multicolumn{3}{|c|}{ Cigarette type } \\
\hline Factory-made only & 558 & 46.0 \\
\hline Roll-your- own only & 366 & 30.2 \\
\hline Both & 283 & 23.3 \\
\hline Not Stated & 6 & 0.5 \\
\hline
\end{tabular}

Note: HSI - Heaviness of Smoking Index (detailed description of how it is derived is stated in the Methods section)

ZMW- Zambian Kwacha (current currency in Zambia)

Table 2. Beliefs about "lights" by brand variety among Zambian smokers, 2012

\begin{tabular}{|c|c|c|c|c|c|}
\hline Beliefs & Total $(n-1,207) \%$ & $\begin{array}{l}\text { "Lights" usual brand } \\
(n-206) \%\end{array}$ & $\begin{array}{l}\text { "Non-light" usual brand } \\
(\mathrm{n}=\mathbf{7 7 8}) \%\end{array}$ & $\begin{array}{l}\text { No usual brand } \\
(n-523) \%\end{array}$ & $\begin{array}{l}\text { PValues (Wald } \\
\text { Chi-square) }\end{array}$ \\
\hline \multicolumn{6}{|c|}{ "Light" cigarettes are less harmful than regular cigarettes } \\
\hline Strongly agree/Agree & 36.5 & 42.1 & 38.2 & 33.1 & \multirow[t]{2}{*}{$\begin{array}{l}p=0.485 \\
(1.74)\end{array}$} \\
\hline $\begin{array}{l}\text { Strongly disagree/Neutral/ } \\
\text { DK }\end{array}$ & 63.5 & 57.9 & 61.8 & 66.9 & \\
\hline \multicolumn{6}{|c|}{ "Light "cigarettes are smoother on throat and chest } \\
\hline Strongly agree/Agree & 42.0 & 50.6 & 44.7 & 36.7 & \multirow{2}{*}{$\begin{array}{l}p=0.013 \\
(16.19)\end{array}$} \\
\hline $\begin{array}{l}\text { Strongly disagree/Neutral/ } \\
\text { DK }\end{array}$ & 58.0 & 49.4 & 55.3 & 63.3 & \\
\hline
\end{tabular}

Note: Percentages are weighted.

DK: Do not know

Table 3. Beliefs about smoothness and harmfulness by brand variety among Zambian smokers, 2012

"Lights"

\begin{tabular}{|c|c|c|c|c|c|}
\hline $\begin{array}{l}\text { "Lights" are smoother on } \\
\text { the throat and chest }\end{array}$ & $\begin{array}{l}\text { "Lights" are less harmful than } \\
\text { regularcigarettes }\end{array}$ & $n$ & $\%$ & $n$ & $\%$ \\
\hline \multirow[t]{2}{*}{ Strongly agree/Agree } & Strongly agree /Agree & 89 & 80.4 & 322 & 81.2 \\
\hline & Strongly disagree /Neutral/DK & 17 & 19.6 & 80 & 18.8 \\
\hline \multirow{2}{*}{$\begin{array}{l}\text { Strongly disagree/Neutral/ } \\
\text { DK }\end{array}$} & Strongly agree /Agree & 5 & 2.8 & 36 & 4.4 \\
\hline & Strongly disagree /Neutral/DK & 95 & 97.2 & 562 & 95.6 \\
\hline
\end{tabular}

Note: DK: Do not know 
Table 4. Predictors of the belief that "lights" are less harmful than regular cigarettes among Zambian smokers, 2012

\begin{tabular}{|c|c|c|c|c|c|c|c|c|c|c|}
\hline & \multirow{2}{*}{$\begin{array}{l}n \text { (total } \\
=1181)\end{array}$} & \multirow{2}{*}{$\begin{array}{l}\text { o who agree } \\
\text { that lights are } \\
\text { less harmfiul }\end{array}$} & \multicolumn{4}{|c|}{ Model 1} & \multicolumn{4}{|c|}{ Model 2} \\
\hline & & & $\begin{array}{l}\text { Odds } \\
\text { Ratio }\end{array}$ & $95 \% \mathrm{CI}$ & p-value & $\begin{array}{l}\text { Type III } \\
\text { Pr ChiSq }\end{array}$ & $\begin{array}{l}\text { Odds } \\
\text { Ratio }\end{array}$ & $95 \% \mathrm{CI}$ & p value & $\begin{array}{l}\text { Type III } \\
\text { Pr ChiSq }\end{array}$ \\
\hline \multicolumn{11}{|c|}{ Gender } \\
\hline Male & 1118 & 36.1 & 1.04 & $0.64-1.71$ & 0.86 & 0.86 & 0.56 & $0.27-1.15$ & 0.11 & 0.11 \\
\hline Female & 66 & 40.4 & Ref & & & & Ref & & & \\
\hline \multicolumn{11}{|c|}{ Age } \\
\hline $15-24$ & 202 & 31.6 & 0.43 & $0.29-0.64$ & $<.0001$ & $<0.001$ & 0.41 & $0.23-0.73$ & 0.002 & \multirow{4}{*}{0.01} \\
\hline $25-39$ & 501 & 40.3 & 0.66 & $0.46-0.95$ & 0.02 & & 0.61 & $0.31-1.19$ & 0.15 & \\
\hline $40-54$ & 280 & 31.7 & 0.51 & $0.33-0.79$ & 0.003 & & 0.59 & $0.19-1.89$ & 0.38 & \\
\hline $55+$ & 201 & 41.1 & Ref & & & & Ref & & & \\
\hline \multicolumn{11}{|c|}{ Income } \\
\hline Moderate & 149 & 34.8 & 0.99 & $0.72-1.36$ & 0.94 & 0.11 & 0.99 & $0.58-1.70$ & 0.98 & \multirow{4}{*}{0.37} \\
\hline High & 308 & 40.6 & 1.02 & $0.63-1.67$ & 0.93 & & 1.18 & $0.73-1.92$ & 0.51 & \\
\hline Not stated & 166 & 46.5 & 1.42 & $0.91-2.23$ & 0.12 & & 1.58 & $0.93-2.67$ & 0.09 & \\
\hline Low & 561 & 34.8 & Ref & & & & Ref & & & \\
\hline \multicolumn{11}{|c|}{ Education } \\
\hline $\begin{array}{l}\text { High } \\
\text { (secondary/ } \\
\text { higher) }\end{array}$ & 449 & 43.5 & 2.09 & $1.11-3.94$ & 0.02 & 0.04 & 1.50 & $0.64-3.50$ & 0.35 & \\
\hline $\begin{array}{l}\text { Moderate } \\
\text { (primary) }\end{array}$ & 606 & 34.5 & 1.81 & $0.83-3.96$ & 0.14 & & 1.20 & $0.56-2.59$ & 0.65 & 0.04 \\
\hline $\begin{array}{l}\text { Low (illiterate/< } \\
\text { primary) }\end{array}$ & 129 & 20.7 & Ref & & & & Ref & & & \\
\hline \multicolumn{11}{|c|}{ Knowledge of health effects } \\
\hline $\begin{array}{l}\text { Knowledge of } \\
\text { health effects of } \\
\text { smoking }\end{array}$ & & & 0.96 & $0.89-1.04$ & 0.34 & 0.34 & 0.93 & $0.85-1.03$ & 0.16 & 0.16 \\
\hline \multicolumn{11}{|c|}{ Health rating } \\
\hline Poor & 121 & 38.7 & 0.95 & $0.40-2.24$ & 0.91 & $<0.0001$ & 0.44 & $0.13-1.46$ & 0.18 & \\
\hline Average & 404 & 43.0 & 1.19 & $0.57-2.52$ & 0.64 & & 0.83 & $0.26-2.67$ & 0.76 & \\
\hline Good & 542 & 31.8 & 0.79 & $0.41-1.55$ & 0.49 & & 0.67 & $0.24-1.86$ & 0.44 & 0.36 \\
\hline No answer & 24 & 28.6 & 0.76 & $0.27-2.13$ & 0.60 & & 0.38 & $0.10-1.46$ & 0.16 & \\
\hline Excellent & 93 & 39.8 & Ref & & & & Ref & & & \\
\hline \multicolumn{11}{|c|}{ Heaviness of Smoking Index } \\
\hline $3-6$ & 322 & 30.5 & 0.64 & $0.40-1.03$ & 0.07 & 0.15 & 0.64 & $0.31-1.32$ & 0.23 & \\
\hline Not stated & 90 & 39.1 & 0.80 & $0.52-1.23$ & 0.31 & & 0.73 & $0.27-1.97$ & 0.53 & 0.44 \\
\hline $0-2$ & 772 & 38.6 & Ref & & & & Ref & & & \\
\hline \multicolumn{11}{|c|}{ Perceived addiction } \\
\hline Yes, somewhat & 449 & 34.4 & 0.74 & $0.55-1.00$ & 0.05 & 0.001 & 0.53 & $0.33-0.84$ & 0.01 & \\
\hline $\begin{array}{l}\text { Yes, very } \\
\text { addicted }\end{array}$ & 393 & 36.4 & 0.91 & $0.56-1.47$ & 0.69 & & 1.03 & $0.52-2.04$ & 0.94 & 0.003 \\
\hline $\begin{array}{l}\text { Not at all } \\
\text { addicted }\end{array}$ & 342 & 38.7 & Ref & & & & Ref & & & \\
\hline
\end{tabular}




\begin{tabular}{|c|c|c|c|c|c|c|c|c|c|c|}
\hline \multicolumn{11}{|c|}{ Smoking damaged health } \\
\hline A little & 352 & 41.5 & 1.45 & $1.00-2.11$ & 0.05 & 0.04 & 0.78 & $0.40-1.52$ & 0.47 & \multirow{4}{*}{0.13} \\
\hline A lot & 278 & 43.4 & 1.71 & $0.83-3.54$ & 0.15 & & 0.91 & $0.42-1.98$ & 0.81 & \\
\hline No answer & 113 & 27.4 & 0.85 & $0.43-1.69$ & 0.65 & & 0.30 & $0.11-0.82$ & 0.02 & \\
\hline Not at all & 441 & 31.1 & Ref & & & & Ref & & & \\
\hline \multicolumn{11}{|c|}{ Smoking will damage health } \\
\hline A little worried & 236 & 38.3 & 1.07 & $0.67-1.71$ & 0.78 & 0.48 & 1.44 & $0.59-3.53$ & 0.42 & \multirow{5}{*}{0.15} \\
\hline $\begin{array}{l}\text { Moderately } \\
\text { worried }\end{array}$ & 145 & 30.1 & 0.77 & $0.34-1.71$ & 0.52 & & 0.89 & $0.31-2.59$ & 0.84 & \\
\hline Very worried & 508 & 39.5 & 1.10 & $0.82-1.46$ & 0.54 & & 1.10 & $0.50-2.39$ & 0.81 & \\
\hline No answer & 28 & 36.7 & 1.31 & $0.44-3.92$ & 0.63 & & 0.63 & $0.20-2.00$ & 0.43 & \\
\hline Not at all worried & 267 & 31.8 & Ref & & & & Ref & & & \\
\hline \multicolumn{11}{|c|}{ Brand Variety } \\
\hline $\begin{array}{l}\text { Lights" usual } \\
\text { brand }\end{array}$ & 203 & 42.5 & 1.00 & $0.50-2.00$ & 0.99 & 0.84 & 0.89 & $0.46-1.74$ & 0.74 & \multirow[t]{3}{*}{0.83} \\
\hline $\begin{array}{l}\text { “Non-lights”usual } \\
\text { brand }\end{array}$ & 470 & 38.0 & Ref & & & & Ref & & & \\
\hline No usual brand & 511 & 32.7 & 0.82 & $0.35-1.91$ & 0.64 & & 1.20 & $0.60-2.42$ & 0.61 & \\
\hline \multicolumn{11}{|c|}{ Cigarette Type } \\
\hline $\begin{array}{l}\text { Factory-made } \\
\text { only }\end{array}$ & 549 & 44.3 & 2.90 & $1.89-4.45$ & $<0.0001$ & $<0.0001$ & 1.57 & $0.64-3.82$ & 0.32 & \multirow{3}{*}{0.57} \\
\hline Both & 278 & 37.6 & 2.15 & $1.29-3.61$ & 0.004 & & 1.37 & $0.67-2.79$ & 0.39 & \\
\hline Hand-rolled only & 357 & 21.9 & Ref & & & & Ref & & & \\
\hline \multicolumn{11}{|c|}{ Lights are smoother } \\
\hline $\begin{array}{l}\text { Strongly agree/ } \\
\text { agree }\end{array}$ & 498 & 81.0 & & & & & 131.13 & $59.4-289.5$ & $<0.0001$ & \multirow{3}{*}{$<0.0001$} \\
\hline $\begin{array}{l}\text { Strongly disagree/ } \\
\text { neutral/ }\end{array}$ & 686 & 4.1 & & & & & Ref & & & \\
\hline Do not know & & & & & & & & & & \\
\hline
\end{tabular}

Outcome Variable Response Options: Light cigarettes are less harmful 'strongly agree/agree' n=443 and strongly disagree/neutral/do not know' n=741. Note: Model 1 AIC (Akaike Information Criterion) = 1537; Model 2 AIC $=749$

for all of the demographic, health knowledge, health beliefs, and smoking-related predictors, the very strong relation between smoothness and harmfulness was strengthened further: Respondents who believed that "lights" are smoother on the throat and chest were much more likely to believe that that "lights" are less harmful than regular cigarettes ( $\mathrm{p}<0.001$, adjusted $\mathrm{OR}=131.13$, 95\% CI 59.4 to 289.5). Additionally, we included one interaction term (i.e., "lights/"non-lights" users * smoothness), into Model 2 to test whether the relation between smoothness and harmfulness beliefs differed for "lights" and "non-lights" users. However, the interaction term was not significant ( $\log$ odds $=0.26$ $\mathrm{p}=0.74$; not shown), indicating that this relation does not differ for "lights" and "non-lights" cigarette users as was shown in Table 3 .

\section{DISCUSSION}

More than one third (36.5\%) of Zambian smokers incorrectly believe that "lights" are less harmful compared to regular cigarettes. The prevalence of this misperception is higher than in Malaysia $(19 \%)^{3}$ but lower than other LMICs such as Thailand $(46 \%)^{3}$ and China $(71 \%)^{2}$. By far the strongest predictor of the misperception that "lights" are less harmful is the belief that "lights" are smoother on the throat and chest $(\mathrm{r}=$ 0.788 , adjusted $\mathrm{OR}=131.13)$. Among those Zambian smokers who believed that "lights" are smoother, $81 \%$ also believed that these cigarettes are less harmful compared to only $4 \%$ of those who did not believe that "lights" were smoother. This strong relation between smoothness and beliefs about lower harmfulness has also been found in an ITC study in China $(\mathrm{OR}=53.87)^{2}$. These findings in Zambia are also consistent 
with those from the UK, Canada, US, and Australia. In all six countries (including China), a very high proportion of tobacco users believe that tobacco products that are smoother are also less harmful. This very strong linkage between smoothness and perception of less harmfulness ${ }^{2,25}$ has been found in every country where this relationship has been investigated. Additionally, our findings showed that although "lights" smokers who believed that "lights" are less harmful were more likely to believe that "lights" are smoother (80.4\%), most "nonlights" smokers (81.2\%) also held similar beliefs. We did not ask about ever use of "lights", and so we do not know whether perceptions of smoothness by "non-lights" users were based on past actual sensory experience with "lights", or whether this is consistent with previous research ${ }^{30,31}$ that showed that perceptions of harm are also influenced by product packaging and marketing (e.g., lighter colors on cigarette packages are perceived as less harmful). The lack of a difference in both beliefs (i.e., smoothness and harmfulness) between "lights" and "non-lights" smokers in our study, demonstrates the strength of the perceived linkage between smoothness and harmfulness. Other factors that were associated with the belief that "lights" are less harmful included: higher levels of education, worrying that smoking had damaged their health, and smoking FM only or both FM and RYO cigarettes. This is likely to be indicative of a lack of public education about the harmfulness of "lights". Typically, those most educated would be expected to be more attentive to factual information about tobacco use related harms ${ }^{32}$, so the reverse finding here, suggests they are incorrectly inferring a reduction in harmfulness. In contrast, those who are more health concerned (worried) tend to be more likely to agree with this belief because of cognitive dissonance ${ }^{33}$. Further public education efforts are needed. Although the proportion of Zambian respondents using "lights" was low, this misperception that "lights" are less harmful was also true among smokers of "non-lights" brands. Given that "lights" have historically been marketed to health concerned smokers ${ }^{6}$, we can expect that "lights" are likely to become more popular as smokers become more health concerned. It is therefore imperative that policymakers act to change misperceptions about "lights" before smokers in Zambia potentially switch to "lights" as a way to reduce their health risks. This includes banning any misleading descriptors e.g., "light", "mild/extra mild" and "low tar", and having persistent educational campaigns to address misperceptions and misleading sensory perceptions of "lights", 34 . Implementing standardized plain packaging to prevent lighter package colors ${ }^{6,35,36}$ or pack shape varieties ${ }^{37}$, may also reduce misperceptions that certain cigarette brands are less harmful. However, it is likely that smokers will continue to infer differences in harmfulness as long as cigarette design features such as filter venting that provide sensations of "lightness/smoothness" 38 are available. The present research, however, suggests that even with plain packaging, there would still be a potent mechanism by which the tobacco industry could continue to communicate with smokers that some cigarettes are less harmful than others: through the sensory experiences (and beliefs about those sensory experiences) of smoking. This therefore reinforces the importance of banning those design features that lead to smoother sensation such as filter venting ${ }^{38}$ and banning additives that are known to reduce harshness and increase smoothness, such as menthol ${ }^{39}$ . One limitation of this study includes under-representation of certain groups within the population, but we accounted for them by conducting weighted analyses. Determining the causal relationship between two correlated variables in a crosssectional study is problematic, and so we can safely state that the findings are consistent, not definitive, with the proposition that smoothness beliefs are causally related to beliefs about harmfulness. Some of this association could be due logically to the opposite causal direction and/or to spuriousness. However, we would suggest tentatively, that the proportion of the association between the two variables that is due to beliefs about smoothness causing beliefs about harmfulness, is likely (much) greater than the proportion due to the opposite causal relation i.e., that beliefs about harmfulness is causing beliefs about smoothness. And with respect to possible spuriousness, it is difficult to imagine any third variables that could produce such a strong $(r=0.79)$, but spurious correlation. The standard potential limitations of self-reports in surveys do not apply here because the main analyses focus on beliefs that smokers hold about smoothness of tobacco products and harmfulness. Selfreport is the only real method of measuring beliefs.

\section{CONCLUSIONS}

The strongest predictor of the misperception that "lights" are less harmful is the belief that "lights" are smoother on the throat and chest. These findings support the conclusion that plain packaging not enough i.e., that to truly decrease misconceptions about the harmfulness of products, it is necessary to ban those design features that lead to smoother sensation such as prohibiting filter venting and banning additives that are known to reduce harshness and increase smoothness, such as menthol. Additionally, Zambian policy makers also need to implement sustained long-term public anti-tobacco education campaigns that focus on the deceptive nature of "lights" by calling the public's attention to industry 
design strategies designed to reduce harshness that are meant to create perceptions that such products are less harmful.

\section{REFERENCES}

1. Borland R, Fong GT, Yong HH, Cummings KM, Hammond D, King $\mathrm{B}$, et al. What happened to smokers beliefs about light cigarettes when «light/mild» brand brand descriptors were banned in the UK? Findings from the International Tobacco Control (ITC) Four Country Survey. Tob Control 2008;17:256-62.

doi:10.1136/tc.2007.023812.

2. Elton-Marshall T, Fong GT, Zanna MP, Jiang Y, Hammond D, O'Connor RJ,et al. Beliefs about the relative harm of «light» and «low tar» cigarettes: findings from the International Tobacco Control (ITC) China Survey. Tob Control 2010;19(Suppl 2):i54-62. doi:10.1136/tc.2008.029025

3. King B, Yong HH, Borland R, Omar M, Ahmad AA, Sirirassamee B, et al. Malaysian and Thai smokers' beliefs about the harmfulness of 'light' and menthol cigarettes. Tob Control 2010;19(6):444-50. doi:10.1136/tc.2009.034256.

4. Kropp RY, Halpern-Felsher BL. Adolescents' beliefs about the risks involved in smoking "light" cigarettes. Pediatrics 2004;114(4):e445-e451. doi:10.1542/peds.2004-0893.

5. Yong HH, Borland R, Cummings KM, Hammond D, O'Connor RJ, Hastings G, et al. Impact of the removal of misleading terms on cigarette pack on smokers' beliefs about Light/Mild cigarettes: Cross-country comparisons. Addiction 2011;106(12):2204-221. doi:10.1111/j.1360-0443.2011.03533.x.

6. Pollay RW, Dewhirst T.The dark side of marketing seemingly "light" cigarettes: Successful images and failed fact. Tob Control 2002;11(Suppl 1):i18-i31. doi:10.1136/tc.11.suppl_1.i18.

7. Djordjevic MV, Stellman SD, Zang E. Doses of nicotine and lung carcinogens delivered to cigarette smokers. J Natl Cancer I 2000;92:106-111. doi:10.1093/jnci/92.2.106.

8. Kozlowski LT, Mehta NY, Sweeney CT, Schwartz SS, Vogler GP, Jarvis MJ, et al. Filter ventilation and nicotine content of tobacco in cigarettes from Canada, the United Kingdom, and the United States. Tob Control 1998;7(4):369-375. doi: 10.1136/tc.7.4.369.

9. O’Connor RJ, Hammond D, McNeill A, King B, Kozlowski LT, Giovino GA, et al. How do different cigarette design features influence the standard tar yields of popular cigarette brands sold in different countries? Tob Control 2008;17(Suppl I):i1-i5. doi:10.1136/tc.2006.019166.10.

10. Kozlowski LT, O'Connor RJ. Cigarette filter ventilation is a defective design because of misleading taste, bigger puffs, and blocked vents. Tob Control 2002;11(Suppl I):i40-i50. doi:10.1136/tc.11.suppl_1.i40

11. Maron DJ, Fortmann SP. Nicotine yield and measures of cigarette smoke exposure in a large population: Are lower-yield cigarettes safer? Am J Public Health 1987;77:546-549. doi:10.2105/AJPH.77.5.546.

12. Hammond D, Collishaw NE, Callard C. Secret science: Tobacco industry research on smoking behaviour and cigarette toxicity. Lancet 2006;367:781-787. doi:10.1016/S0140-6736(06)68077- X.

13. Harris JE, Thun MJ, Mondul AM, Calle EE. Cigarette tar yields in relation to mortality from lung cancer in the cancer prevention study II prospective cohort, 1982-8. BMJ 2004;328(7431):72-78. doi:10.1136/bmj.37936.585382.44.
14. Hecht SS, Murphy SE, Carmella SG, Li S, Jensen, J, Le C, et al. Similar uptake of lung carcinogens by smokers of regular, light, and ultralight cigarettes. Cancer Epidem Biomar 2005;14(3):693-698. doi:10.1158/1055-9965.EPI- 04-0542.

15. Thun MJ, Burns DM. Health impact of "reduced yield" cigarettes: A critical assessment of the epidemiological evidence. Tob Control 2001;10(Suppl 1):10i4-i11.

doi:10.1136/tc.10.suppl_1.i4

16. Yang G, Wang Y, Wu Y, Yang J, Wan X. The road to effective tobacco control in China. Lancet 2015;385:1019-1028. doi: 10.1016/S0140-6736(15)60174- X.

17. World Health Organization. Global progress report on implementation of the WHO Framework Convention on Tobacco Control. Geneva. Switzerland. WHO, 2012.

18. World Health Organization. The WHO Framework Convention on Tobacco Control:10 Years of implementation in the African Region. WHO, 2015. Available from: http://www.afro.who.int/ index.php?option=com_docman\&amp;task $=$ doc_download\&gid =9632\&Itemid=2593 (accessed February 2016).

19. World Health Organization. Policies for tobacco control in the African Region.Brazzaville:WHO Regional Office for Africa. WHO, 2013.

20. Blecher EH, Ross H. Tobacco use in Africa: Tobacco control through prevention. Atlanta, GA: American Cancer Society. 2013.

21. Central Statistical Office (CSO) [Zambia], Ministry of Health $(\mathrm{MOH})$ [Zambia], and ICF International. Zambia Demographic and Health Survey 2013-14. Rockville. Maryland, USA: Central Statistical Office, Ministry of Health, and ICF International. 2014.

22. Salloum RG, Goma F, Chelwa G, Cheng X, Zulu R, Kaai SC, et al. Cigarette price and other factors associated with brand choice and brand loyalty in Zambia: findings from the ITC Zambia Survey. Tob Control. 2015;24(Suppl 3):iii33-iii40.

doi:10.1136/tobaccocontrol-2014- 051878

23. World Health Organization. Parties to the WHO Framework Convention on Tobacco Control. WHO, 2016. Available from: http://www.who.int/fctc/signatories_parties/en/(accessed March 2016).

24. ITC Project. ITC Zambia National Report. Findings from the Wave 1 (2012) Survey. Waterloo: ITC, 2014a. Available from: http://www. itcproject.org/files/ITC_ZambiaNR-ENG- FINAL- web_May2014. pdf (accessed January, 2016).

25. Elton-Marshall T, Fong GT, Yong HH, Borland R, Xu SS, Quah AC, et al. Smokers sensory beliefs mediate the relation between smoking a'light/low tar' cigarette and perceptions of harm. Tob Control 2014;0:1-7. doi:10.1136/tobaccocontrol-2014- 051977.

26. Fong GT, Cummings KM, Borland R, Hastings G, Hyland A, Giovino GA, et al. The conceptual framework of the International Tobacco Control (ITC) Policy Evaluation Project. Tob Control 2006;15(Suppl 3):iii3-11. doi:10.1136/tc.2005.015438.

27. ITC Project.Wave 1 (2012) ITC Zambia Technical Report. Waterloo:ITC, 2014b. Available from: http://www.itcproject.org/ files/ITC_Zambia_Wave_1_Technical_Report_-FINAL- rev-May9. pdf (accessed January 2016).

28. Chaiton MO, Cohen JE, McDonald PW, Bondy SJ, et al. The Heaviness of Smoking Index as a predictor of smoking cessation in Canada. Addict Behav 2007;32:1031-1042. doi:10.1016/j.addbeh.2006.07.008.

29. Kozlowski LT, Porter CQ, Orleans CT, Pope MA, Heatherton T. Predicting smoking cessation with selfreported measures of 


\section{Research Paper}

nicotine dependence: FTQ, FTND, and HSI. Drug Alcohol Depen 1994;34(3):211-216.

30. Hammond D, Dockrell M, Arnott D, Lee A, McNeill A. Cigarette pack design and perceptions of risk among UK adults and youth. Eur J Public Health 2009;19(6):631-637.

doi:10.1093/eurpub/ckp122.

31. Pollay RW. The role of packaging seen through industry documents. Expert Report prepared for: JTI-Macdonald, Imperial Tobacco Canada Ltd and Rothmans, Benson \&amp; Hedges Inc. v. Attorney General of Canada and Canadian Cancer Society (intervenor). Supreme Court, Province of Quebec, District of Montreal. Defense Exhibit D-116. 2001.

32. Siahpush M, McNeill A, Hammond D, Fong GT. Socioeconomic and country variations in knowledge of health risks of tobacco smoking and toxic constituents of smoke: results from the 2002 International Tobacco Control (ITC) Four Country Survey. Int. J. Environ. Res. Public Health 2006:8(6), 2170-2180.

doi.org/10.3390/ijerph8062170

33. Fotuhi O, Fong GT, Zanna MP, Borland R, Yong HH, Cummings KM. Patterns of cognitive dissonance-reducing beliefs among smokers: a longitudinal analysis from the International Tobacco Control (ITC) Four Country Survey. Tob. Control 2013:22,52-58. doi:10.1136/tobaccocontrol-2011- 050139

34. Shiffman S, Pillitteri JL, Burton SL, Rohay JM, Gitchell JG. Smokers" beliefs about «Light» and «Ultra Light» cigarettes. Tob. Control 2001;10:i17-i23.

doi: 10.1136/tc.10.suppl_1.i17

35. Bansal-Travers M, O'Connor R, Fix BV, Cummings KM. What do cigarette pack colors communicate to smokers in the U.S.? Am J Prev Med 2011;40(6):683-689. doi:10.1016/j.amepre.2011.01.019.

36. Wakefield M, Morley C, Horan JK, Cummings KM.The cigarette pack as image: New evidence from tobacco industry documents. Tob Control 2002;11:i73-i80. d

oi:10.1136/tc.11.suppl_1.i73.

37. Kotnowski K, Hammond D. The impact of cigarette pack shape, size and opening: Evidence from tobacco company documents. Addiction 2013;108:1658-1668.

doi:10.1111/add.12183.

38. O'Connor RJ, Caruso RV, Borland R., Cummings KM, BansalTravers M, Fix BV. Relationship of cigarette-related perceptions to cigarette design features: findings from the 2009 ITC U.S. Survey. Nicotine Tob Res 2013;15(11): 1943-1947. doi:10.1093/ntr/ntt075.

39. Tobacco Products Scientific Advisory Committee (TPSAC) (2011). Menthol cigarettes and public health: Review of the scientific evidence and recommendation. Available from http://www.fda.gov/ downloads/AdvisoryCommittees/CommitteesMeetingMaterials/ TobaccoProductsScientificAdvisoryCommittee/UCM269697.pdf (accessed February 2016).

\author{
ACKNOWLEDGEMENT \\ The authors would like to \\ acknowledge the ITC Zambia \\ fieldwork team who conducted \\ the survey interviews and \\ those who translated the \\ questionnaires. Special thanks \\ to Mr.Richard Zulu, Ms. \\ Josephine Chewe and Mr. John \\ Mayeya for their contributions \\ in planning and implementing \\ the ITC Zambia Survey.
}

CONFLICT OF INTEREST

All the authors have completed and submitted the ICMJE Form for Disclosure of Potential Conflicts of Interest and none were reported.

\footnotetext{
FUNDING

This work was supported by an operating grant from the Canadian Institutes of Health Research (115016). Additional support was provided to GTF from a Senior Investigator. Award from the Ontario Institute for Cancer Research and a Prevention Scientist Award from the Canadian Cancer Society Research Institute. ACG was supported by the CIHR. Banting and Charles Best Canada Graduate Scholarship and by a Doctoral Scholarship from the CIHR Training Grant in Population Interventions for Chronic Disease Prevention (PICDP). These funders had no role in: the study design, collection, analysis, interpretation of data, writing the manuscript, and the decision to submit the manuscript for publication.

CONTRIBUTORS STATEMENT SCK was the lead author. All authors contributed, reviewed and revised various drafts of the paper. All authors approved the final manuscript.

PROVENANCE AND PEER REVIEW

Not commissioned; externally
} peer reviewed. 